\title{
EtNografía de ARCHIVOS ADMinistrativos. Un corpus de demandas y quejas menores en un barrio de vivienda social
}

\author{
EMILIA SCHIJMAn \\ Licenciada en Sociología por la Universidad de Buenos Aires, UBA y magíster \\ pOr la École Normale Supérieure/École des Hautes Etudes en Sciences Sociales, \\ PARís \\ emilia.schijman@hotmail.com
}

\begin{abstract}
Resumen
Apartir de una investigación etnográfica en una cité de la periferia parisina, este Martículo propone una discusión metodológica en torno al análisis de un corpus de escritos encontrados in situ: un cuaderno de peticiones en una ventanilla pública que informa sobre la renovación urbana en curso y centenares de cartas dirigidas a la institución de vivienda social. El objetivo es interrogar este archivo administrativo en tanto documento etnográfico, abordando las diferentes escalas de análisis que supone (etnográfica, sociológica, histórica). Una vez descifrado el expediente administrativo, el artículo describe ciertos rasgos particulares del hábitat popular: conflictos, peticiones sucesivas, quejas y recriminaciones.

Palabras Clave: archivos administrativos, escritura menor, etnografía, vivienda social
\end{abstract}

\section{ETHNOGRAPHY OF ADMINISTRATIVE FILES. REQUESTS AND MINOR COMPLAINTS}

IN A SOCIAL HOUSING DISTRICT

\begin{abstract}
This paper, an ethnographic research in a town of Paris' periphery, presents a methodological debate regarding the analysis of a set of writings found in situ: a notebook for requests in a public window that informs about the ongoing urban renovation and about hundreds of letters sent to the social housing institution. The aim is to examine the administrative files as an ethnographic document that involves different scales of analysis (ethnographic, sociological, historiographical). Once files are decoded, the article describes some traits of the popular housing: conflicts, successive requests, complaints and recriminations.
\end{abstract}

Revista Colombiana de Antropología

Volumen 46 (2), julio-diciembre 20I0, pp. 279-305 
KEYWORDS: administrative files, "ordinary writing”, ethnography, social housing

Pl 30 de enero de 2005 se abre un cuaderno en una oficina des-

- tinada a los habitantes de una cité francesa (infra "un barrio

Lpopular”), con el fin de recoger sus apreciaciones sobre la operación de renovación urbana en curso. La Municipalidad, el organismo que gestiona la vivienda social y la Comunidad de Aglomeración tienen un proyecto conjunto: rehabilitar las viviendas, remodelar las calles peatonales, demoler dos torres para construir inmuebles más pequeños y más cómodos y abrir nuevos comercios y equipamientos colectivos. El proyecto está subvencionado por la Agencia Nacional de Renovación Urbana y se inscribe en un ambicioso programa que involucra los barrios de vivienda social más pobres de Francia. Por medio de la acción urbana (embellecimiento, demolición y construcción de vivien-

I. Para un análisis de las operaciones del Programa Nacional de Renovación Urbana, ver S. Faure, S. Faure (2006).

2. Mis sinceros agradecimientos a Jean François Laé por su valiosa contribución en la elaboración del artículo. El trabajo que aquí se presenta es una reflexión metodológica sobre el uso de "archivos menores" en las ciencias sociales. Se basa en una etnografía (2008-20I0) en un barrio de vivienda social situado en la periferia norte de París. Traducción del francés: Diego Milos. das más refinadas) y de operaciones de realojamiento en otros barrios, el programa intenta contrarrestar la mala reputación de estas urbanizaciones y atraer hacia ellas habitantes de condición social más alta. ${ }^{1}$

Desde el comienzo, en pos de registrar las reacciones de los habitantes ante los planos, dibujos y croquis expuestos en la oficina, su responsable, Hélène, anota en una libreta algunas palabras, informaciones, réplicas de las familias en un estilo telegráfico, es decir, sin redacción de frases. “¿Qué opina usted?”, pregunta con frecuencia a las mujeres, a las madres y a los niños que pasan. ${ }^{2}$

En una primera lectura me sorprendió que los habitantes no respondieran con exactitud a la pregunta que se les formulaba sino que la tergiversaban convirtiendo el cuaderno en libro de quejas. Si se espera que manifiesten sus opiniones para luego hacer modificaciones accesorias al proyecto del barrio, ellos exigen, en respuesta, que se anote lo dicho. Así, el 5 de febrero de 2005 Hélène escribe: "La Sra. está cansada de los ruidos en los departamentos vecinos. Nunca vacían los basureros y los olores suben hasta su departamento. Pide que se haga algo". 
La cité fue construida hace más de 30 años en una ciudad ubicada en la periferia norte de París. El parque agrupa 2045 viviendas destinadas al alquiler y pueden transmitirse en línea ascendente o descendente al interior de las familias. Como el déficit de viviendas es importante, y porque su valor, en términos de seguridad social, es considerable, gran parte de los departamentos están superpoblados. Los 78I3 habitantes que censan las estadísticas locales excluyen en realidad todos aquellos que viven en "situación de irregularidad", a la espera de un título de arrendamiento: los familiares o amigos alojados, los inquilinos que subalquilan un cuarto y las personas que ocupan sin título los departamentos liberados.

La economía general de la cité se caracteriza hoy por una proporción importante de familias pobres, desafiliadas del salariado estable (Castel, R., I995). Un 54\% de las personas activas están desempleadas, y solo un $29 \%$ poseen un empleo estable (Insee/ DIV, Fiche Profil - Quartiers de la Politique de la ville, I999). En este contexto, las ayudas sociales forman una parte importante de los recursos familiares. Apenas el Estado deposita en las cuentas bancarias el Ingreso Mínimo de Inserción, RMI, el Ingreso Mínimo para la Vejez, MV, las subvenciones para las familias monoparentales o para los adultos discapacitados, el banco de la cité se colma. Cada uno retira hasta el último billete para abastecer los refrigeradores, pagar los servicios (luz, gas), devolver un préstamo o pagar el arriendo. La plata se va muy rápido: tres de cada diez inquilinos tienen deudas de alquiler.

En este barrio, los lazos comunitarios y familiares forman las mallas de una protección que amortigua un poco las dificultades que pesan sobre los pobres económicos. El hecho familiar es masivo y concierne tanto a los franceses como a los habitantes provenientes de Senegal, Mali, Islas Comoras, Costa de Marfil, Argelia, Marruecos y Haití. La proporción de jefes de hogar de origen extranjero llega al 40\% del total, pero con frecuencia, sus hijos son franceses. Nótese que los jóvenes menores de 20 años representan más de un tercio de la población del barrio (39\%).

Del contraste entre la finalidad de la oficina y la toma de la palabra y de la escritura por parte de los habitantes surge la idea de explorar el documento. ¿Sobre qué nos informa el cuaderno? ¿Cómo pueden esclarecer estos escritos las observaciones paralelas que registro en el barrio? ¿Cuáles son las mayores preocupaciones que incitan a los habitantes a visitar esta oficina? ¿De qué manera lo que allí se manifiesta modifica y talla brutalmente los problemas cotidianos? ¿Y si se tratara simplemente de una huella 
de los diferentes recorridos de las familias en los laberintos de las ventanillas? ${ }^{3} \mathrm{Si}$ hubiera otros cuadernos en otras ventanillas, ¿encontraríamos formulados problemas equivalentes? ¿De la misma manera? ¿Accederíamos a los mismos relatos?

Es imposible acceder a la vivienda social sin antes escribir, contestar y redactar. Es imposible reclamar un derecho sin antes llenar un formulario. Los modos de acceso a derechos suponen una acumulación gráfica: certificados, explicaciones, respuestas a instrucciones a fin de dejar registradas las solicitudes, las demandas (Pohn, A., 2009; Siblot, Y., 2005). Hay que contar una y otra vez su vida, la historia de su familia, de la vivienda, del trabajo. Es muy difícil acceder

3. Traducimos la palabra guichet como "ventanilla", la única que parece dar cuenta en español de ese espacio intermedio presente en las oficinas públicas, que une y separa los corredores interiores de las instituciones, de los individuos ordinarios que a ellas recurren. La palabra en español resulta problemática por su carácter polisémico.

4. Ver, por ejemplo, las cartas de desempleados pidiendo el mantenimiento del subsidio por paro, analizadas por J-F. Laé (2008b). al conjunto de derechos sociales a través de simples formularios administrativos, porque los derechos toman en cuenta la singularidad de los casos, los recursos disponibles y la composición de las familias. Para mostrarse elegible es necesario contar un relato biográfico y familiar. ${ }^{4}$ Para cada derecho (vivienda social, seguridad social, ayuda jurídica, mínimo vejez, ayuda para familias monoparentales, subsidio adultos discapacitados, entre otros) es importante redefinir su situación y la de sus allegados (Dubois, V. 1999; Weller, J. M., I999). Cada una de estas definiciones supone competencias en la producción de legajos específicos, un aprendizaje de las diferentes categorías jurídicas, de los modos de presentación de sí, una acumulación de escritos, documentos, actuaciones y papeles que atestigüen las situaciones. En este sentido, una red de escrituras atraviesa el conjunto de las instituciones sociales. Podríamos reconstruir, por ejemplo, la historia de una familia y de sus solicitudes a partir de todas su correspondencia. Pensemos en los casos de desalojo. Este acontecimiento provoca un conjunto de correspondencia dirigida a diversas autoridades: la asistente social, el organismo de vivienda social, la Municipalidad, el agente de justicia (huissier), entre otros. Como el procedimiento legal es largo (puede durar hasta 18 meses), cada autoridad puede intervenir en un eslabón de la cadena de expulsión. Por otro lado, los inquilinos recibirán correos de aviso, de advertencia, de requerimiento, de información sobre derechos, etc. A través de esta red de escrituras 
las familias aprenderán al mismo tiempo los procedimientos, las maneras de contestar, de defenderse, de apelar, de definirse para estar más protegidos. ${ }^{5}$

Estamos acostumbrados a pensar que esta masa documental es una simple burocracia y que no tiene mayor interés que el de clasificarla en tipos de formularios o cuestionarios. Sin embargo, si la abordamos desde un punto de vista etnográfico, estos escritos (borradores de profesionales, cartas de solicitud, informes administrativos) se aclaran bajo

\begin{abstract}
5. Las expulsiones afectan, de forma masiva, a las clases populares. Podríamos pensar que lo mismo ocurre con los asuntos civiles o penales tratados en justicia. Por su fragilidad, son también las clases populares quienes solicitan al Estado Social, lo que significa que están más implicadas que las clases superiores en la producción de legajos.
\end{abstract} una nueva luz. Puesto que los individuos escriben y relatan incidentes, develan posturas mentales, el etnógrafo puede descubrir allí maneras de pensar y de acomodarse a las reglas sociales. En lo que aquí nos concierne, la vivienda es un enorme acumulador de escritura. Los mil expedientes individuales archivados en las oficinas de los organismos habitacionales contienen 20030 años de relaciones contractuales con los propietarios. Se trata de biografías administrativas donde quedan registradas el crecimiento de los hijos, las alianzas y separaciones, los alojamientos provisorios de amigos o miembros de la familia, las pérdidas de empleo, los endeudamientos, la insalubridad en los cuartos o el deterioro de los ascensores. Así, todas las dificultades familiares — del trabajo a la justicia, de las separaciones conyugales a los conflictos con los vecinos -emergen del corpus. En la interfase de los escritos populares y de las lógicas institucionales se revelan puntos neurálgicos que manifiestan quejas, exigencias y recriminaciones. Lo dicho se transforma en escrito, luego en cuaderno de notas, más tarde en archivo.

El carácter "vivo" de estos archivos permite al etnógrafo encontrarlos en el terreno, leerlos e interpretarlos. Los archivos, visibles en los escritorios, disponibles en los armarios y en los cajones de cualquier institución, presentan la ventaja de ser soporte de una comunicación entre individuos e instituciones que se produce fuera de la intervención del sociólogo, proporcionándole a la investigación información de una naturaleza muy diferente a la que caracteriza a las observaciones y entrevistas.

Este tipo de escritos son los que abordaré. A través de una lectura atenta, en las páginas que siguen intentaré desentrañar tanto 
las dificultades encontradas en su lectura y análisis como las pistas que se abren para la investigación. Por esa vía, y siguiendo trabajos recientes sobre las escrituras ordinarias o "menores" (Artières, P., I998, 2000; Fabre, D., I993, I997; Laé, J-F., 2008a; Lahire, B., I993), se vuelve posible cuestionar la censura interna a las ciencias sociales entre el historiador, "experto" en archivos y documentos personales, y el sociólogo, "experto" en interacciones cara a cara.

Los materiales que presento han sido recogidos durante una investigación de campo en un barrio de vivienda social situado al norte de la región parisina (2008-20I0). El cuaderno fue encontrado en la oficina de un Proyecto de Renovación Urbana en la que, a lo largo de varias semanas de visita, fui negociando su lectura in situ: “¿Estás segura de querer comenzar por esto?”, me preguntaba la responsable del lugar. Desde su perspectiva, el carácter "privado" y sin valor particular la llevaba a una cierta reticencia: ¿por qué perder tiempo en leerlo? Sin embargo, la confianza establecida con ella me permitió llevar a cabo una primera lectura en la oficina y, luego, habilitó el préstamo del cuaderno. El acuerdo se realizó con una promesa: mantener el secreto o al menos gran discreción.

El segundo tipo de material utilizado es un conjunto de cartas de inquilinos encontradas en la carpeta denominada "correo" de los expedientes locativos. El acceso, facilitado por la responsable del organismo, es excepcional desde el punto de vista jurídico, pero frecuente cuando se tejen lazos densos en el terreno y se

6. En Francia, el artículo 6 bis de la Ley del I7 de julio de 1978 dispone que los documentos administrativos cuya comunicación atentaría "al secreto de la vida privada" pueden mantenerse bajo reserva. El artículo 7 de la Ley del 3 de enero de 1979 fija un plazo de I2O años a partir de la fecha de nacimiento para la comunicación de archivos públicos que contengan expedientes personales. construye confianza. ${ }^{6}$ Allí, propuse un pequeño tratamiento estadístico de una serie de 300 expedientes a fin de despejar ciertas constantes: tamaño de las familias, composición socioprofesional, antigüedad en la vivienda, tasa de endeudamiento

y motivos reales que subyacen a los pedidos de cambio de departamento. Por esta vía los profesionales aceptaron con facilidad que me sumergiera en los archivos. Por lo demás, se me propuso realizar una pasantía en el organismo con el objetivo de cubrir los gastos de mi actividad. La posición de pasante es privilegiada para el sociólogo, pues le otorga un estatus fiable y muy ventajoso para sus movimientos de consulta, fotocopias y acceso a diferentes repisas e informes. Además, dicho estatus justifica las 
observaciones al momento de la recepción de correos: uno puede recoger comentarios candentes, rumores sobre tal o cual familia, urgencias repentinas que deben ser resueltas, reflexiones sobre lo que se debe hacer o no frente a un caso determinado. En contrapartida, esta situación permite al sociólogo presentar hipótesis espontáneas para discutirlas con los mismos profesionales. ${ }^{7}$
7. Adquirir el estatus de practicante ofrece también otras posibilidades: derecho a tener copia de las llaves para entrar cualquier día de la semana, se le permite el uso del lugar y de los escritorios, tener acceso a los programas computacionales y a los datos estadísticos y, sobre todo, tener la libertad de interactuar y plantear las preguntas, hasta las más triviales, a los 25 profesionales que allí trabajan. Esta posición deriva de la confianza depositada. De esta forma, mi calidad de practicante me permitió conocer a otros agentes y otras oficinas, que me abrieron las puertas en razón de ello. Una simple llamada telefónica de la responsable de la agencia a los guardias y recepcionistas bastaba para que aceptaran mi visita.

\section{El cuaderno de LA \\ RenOVACIÓN DEL BARRIO}

amos al problema de la decodificación del cuaderno encon-
trado. Si seguimos los procedimientos de los historiadores,
la primera operación consistiría en describir la materialidad del documento. El cuaderno contiene 72 páginas "garabateadas" con bolígrafo en las que, en el encabezado, figura la fecha del día, separada del día siguiente mediante un trazo grueso al momento del cierre de la oficina. Cada página está dividida en dos columnas verticales. En la primera se indica el nombre de las personas que se acercaron al lugar, el nombre del edificio y el piso en el que viven. En la segunda se anotan los comentarios de los habitantes o las observaciones de Hélène, en una caligrafía distendida y con abreviaciones personales, a menudo incomprensibles en una primera lectura. Pero este orden de columnas y días no deja de ser frágil: a veces una miríada de informaciones desborda las líneas hasta el punto de confundir su lectura. Por ejemplo, cuando las demandas o las recriminaciones al organismo de vivienda social y al Proyecto Urbano se mezclan con las urgencias, los nombres, las direcciones, los números de teléfono y las demandas de contacto con tal o cual institución.

Para Hélène, llevar este registro es una manera de "conocer cuál es la demanda", de conservar la memoria de la cantidad de visitas diarias, semanales y mensuales y así poder hacer balances anuales y demostrar la utilidad de la oficina. La mayoría de las 
veces estos apuntes son realizados en lo inmediato, frente a las familias o los habitantes que observan cómo escribe el profesional. Para ellos, la escritura funciona como un sello de garantía: la palabra escrita es una promesa y un derecho de respuesta (Laé, J-F., 2008a). Promesa en el sentido de que la demanda no será olvidada y derecho porque hay un compromiso a responder a la misma. Así, la escritura vuelve perenne la demanda; olvidarla sería una falta, un error, porque está escrita: “¿Anotó usted bien?”, pregunta alguno de vez en cuando. "¿Tiene usted noticias sobre el realojamiento?”, pregunta otro. Un tercero se retira de la oficina confiado, su problema será por fin considerado:

$\mathrm{N}^{\mathrm{o}}$ I Plaza Molière. Viene por su hermana que vive en el sector 3 Béranger. Problema de reflujo del WC. Inundaciones en el departamento. Vinieron los bomberos. Tel. Servicio higiene Municipalidad, número ocupado. Hermana enfermedad grave. Seguimiento: H. Cochin.

A veces aparece un número de teléfono, sea del inquilino, del portero del edificio o de un servicio social para activar una ayuda, llamar o proponer una orientación a la Municipalidad, a la Oficina de vivienda social o a alguno de sus intermediarios.

Para la autora del cuaderno, el mismo tiene tres vertientes. Una es personal, otra tiende hacia el público y la tercera, comunica con los socios institucionales. Podríamos apuntar una cuarta vertiente, relacionada con los contactos necesarios con otras oficinas, como por ejemplo sobre las urgencias. Estas

8. Esta observación es importante, pues todos los cuadernos atravesados por varias líneas de tensión son difíciles de leer. En toda institución podemos encontrar estos niveles de escritura, relacionados con preocupaciones contradictorias. Por un lado, hay que transcribir lo que dice la gente, a menudo en su enunciación inmediata y, por otro lado, hacerlo en un lenguaje técnico, con el propósito de comunicar con facilidad la información urgente. cuatro direcciones se mezclan y obstaculizan la decodificación del cuaderno. ${ }^{8}$

En resumen, ¿qué aspecto tiene este cuaderno? Se trata de una escritura profesional que informa, ante todo, sobre el trabajo social y multifacético realizado en una oficina pública de un barrio popular. Sin embargo, las palabras retranscritas resuenan al leer las cartas que los mismos envían con regularidad al organismo de vivienda para resolver diferentes tipos de problemas. 


\section{LAS CARTAS DE LOS INQUILINOS}

sta segunda serie de materiales está compuesta de Ioo cartas - de inquilinos dirigidas al organismo de gestión locativa. Se - encuentran repartidas en los expedientes archivados a lo largo de 40 años, una compilación de la sucesión de relaciones entre arrendadores y arrendatarios. Para realizar un tratamiento cuantitativamente razonable escogí los expedientes de dos edificios correspondientes a cerca de 250 viviendas.

$\mathrm{Al}$ abrir el expediente de un inquilino se encuentran carpetas de diferentes colores en las que se archivan, por separado, los trabajos técnicos efectuados en la vivienda, los contratos firmados, las cartas recibidas y enviadas, así como una carpeta dedicada especialmente al seguro de la vivienda. Los habitantes escriben en abundancia, a pesar de que las competencias escolares suelan ser pocas y la correspondencia carezca de revisión [sic]. No por ello dejan de expresar sus enojos, pasiones y súplicas en estilos muy heterogéneos. El aprendizaje sobre la marcha predomina cuando hay que dirigirse a la administración para conseguir una respuesta a una serie de urgencias. ${ }^{9}$

Podríamos llamar administrativos a estos expedientes, dado que administran una relación contractual compleja que atañe al contrato de arriendo, a la seguridad, al mantenimiento del departamento, a las relaciones de vecindad y al pago adecuado de los alquileres. Cuando surgen conflictos, disputas, quejas y reclamos, los inquilinos escriben y reciben respuestas. Sin embargo, bajo su apariencia formal, se filtran otros elementos entre los cuales encontramos relatos biográficos. Las cartas puntuan los acontecimientos familiares (fallecimientos, matrimonios, rupturas, despidos laborales, nacimientos, enfermedades, problemas judiciales, etc.) y se inscriben en un amplio espectro de intercambios, donde participan la policía, la justicia, el municipio y los servicios sociales. ${ }^{10}$ Por ejemplo, en estos escritos encontramos decisiones de justicia en torno a cuestiones ajenas a las de

9. B. Lahire subraya en su obra La raison des plus faibles la dificultad para establecer correlaciones entre la existencia de ciertas prácticas de escritura y de criterios sociológicos, tales como el nivel de estudios y el origen social: "Nos damos cuenta, dice el autor, que es casi imposible despejar recurrencias evidentes". (Lahire, B., I993, I3O).

IO. Para el observador latinoamericano, la omnipresencia de tantas instituciones funcionando en red, regulando y controlando de cerca la vida de las personas, es sorprendente. Si se remite a los orígenes del estado moderno francés, hay que señalar que es también el resultado, más reciente, de la pregnancia del derecho social en toda la sociedad. 
vivienda, notas realizadas por porteros, técnicos y vecinos relativas al orden público o a la higiene general de los arrendatarios; también hay informes de asistentes sociales, notarios, empresas de seguros, comisiones nacionales de sobreendeudamiento. Esta intercalación de lo privado y lo administrativo llamó mi atención: ¿por qué contar nuestra vida familiar cuando nos encontramos en relaciones contractuales? ¿Por qué tanta investidura personal en un correo administrativo? Y, a la inversa, ¿por qué tantos imperativos sociales pasan por la oficina de vivienda social? El espesor del expediente viene de esta coelaboración en la que cada parte presenta sus pruebas. De ambos lados la literatura es copiosa y nos informa no solo sobre las relaciones entre inquilinos administradores sino que, más allá de estas, sobre las trabas puestas por un lado y las estrategias inventadas para movilizar diferentes ventanillas por otro.

Entiendo que este corpus esclarece con una nueva luz las anotaciones del cuaderno precedente, principalmente en lo que refiere a los recorridos por las ventanillas y a las condiciones de vida en la cité. Con el cuaderno teníamos una sola superficie de escritura; con los expedientes se abre un horizonte más amplio: un conjunto de pruebas, certificados, huellas de procedimientos y de recriminaciones presentadas en otras ventanillas. Ya no se trata aquí de una escritura abreviada, breve y parcial. Por el contrario, se trata de verdaderas cartas que desarrollan punto por punto un conjunto de dificultades, diputas y desacuerdos. Así como el cuaderno dejaba huellas de pasos fugaces, tenemos ahora documentos de una duración más larga, relativos a todo un ciclo de vida, una auténtica memoria familiar-administrativa.

\section{LA LECTURA DE LAS QUEJAS Y LOS RECLAMOS}

\section{Descifrar notas y borradores}

Qué se escribe en este cuaderno? A grandes rasgos, urgencias:
inundaciones en los departamentos, sobrepoblación, miembros
de la familia que se encuentran sin alojamiento y que hay
que albergar provisoriamente, mohos en las paredes y daños de
ascensor, intimidades deshechas, conflictos familiares, etc. Son
estas, entre tantas otras, las urgencias que incitan a los habitantes 
a presentarse a la ventanilla para conseguir una intervención lo más pronto posible. Se trata de súplicas, protestas y sentencias de las que se espera respuestas o soluciones posibles, deseadas o necesarias. Los pasantes cuentan sobre las transformaciones de la familia, hablan sobre la escolarización de los niños e incluso, a veces, sobre acontecimientos graves y dolorosos, como puede leerse en esta anotación :

I habitante 7 calle Lamartine 2 hijos 3I años + I acb. Bastante triste. Único desplazamiento a las Antillas para transportar el cuerpo de su hijo. Niño muerto a cuchillazos en 1996 en Carrefour. Está enterrado en el Cementerio de la comuna...

En un plano general de lectura, el tema de las urgencias puede resumirse así: de las 224 visitas registradas en el cuaderno de la encargada, 2/3 implican alguna demanda de vivienda (un techo, un departamento más grande o uno más pequeño), alguna indicación de problemas técnicos o de conflictos en los espacios públicos, $35 \%$ y $32,6 \%$ respectivamente. Las familias pasan un cuarto de hora aparentando mirar la exposición de los planos urbanos expuestos en las paredes, pero tienen en mente "sus problemas".

Apenas siente que se acerca una persona, Hélène deja de trabajar en el computador ubicado en la esquina del local, se dirige hacia la puerta y la invita a pasar, como a la Sra. Lafite, quien, tímidamente, se decide a entrar. Está al tanto de la renovación y pregunta a la encargada cuáles serán las próximas demoliciones para saber si su edificio está involucrado. Sin duda alguna, ella quiere mudarse y la demolición será su oportunidad. Pero, ¿para ir a dónde? Se la percibe inquieta. Muy pronto, vuelve a la situación presente. Algo agitada, cuenta que hace dos días que el ascensor no anda y que debe subir los I5 pisos de su edificio con sus compras, dos kilos de arroz y cinco litros de leche por lo menos y subirlos, nuevamente, después del almuerzo con sus dos hijos que vuelven de la escuela. No es el primer desperfecto del ascensor, exclama. El verano pasado la cité fue un gran y absoluto desperfecto técnico: no funcionó ninguno de los ascensores del recinto durante un mes.

Además, viven tres personas en dos ambientes, "estamos apretados", dice. Cada cuatro meses ella hace el recorrido por las ventanillas: ha renovado varias veces su solicitud para un departamento de tres o cuatro piezas, siempre en el mismo sector 
ya que su tía vive a pocos metros de su casa. Llenó el formulario de demanda y lo envió a la sede central del organismo, se dirigió luego a la sede situada en el barrio, se presentó en la recepción, vio varias veces al guardia para enterarse de las viviendas vacantes. Incluso una vez pensó en escribir al Ministro de la Vivienda. "Ya no puedo más. Estoy harta", dice. "Lo entiendo", responde Hélène y le avisa: "Yo anoto todas las demandas, pero su edificio no será demolido así que por el momento usted no será realojada”. Decepción. En el momento en que Hélène toma la pluma, la Sra. Lafite se pone incisiva: "Soy madre soltera de dos niños menores de edad, ¿por qué no soy prioritaria?” La inquilina mira cómo Hélène escribe, como si validara así su demanda, un "certificado exacto", y manifiesta cierto alivio. El cuaderno se le aparece como una garantía de seriedad y de que se harán cargo de su "urgencia". Aunque ella sepa que la ventanilla no está allí para ese tipo de asuntos, al menos registra una huella que podría ser leída por otros servicios:

I mujer número 54 calle Verlaine. Dos niños cuatro años. 25 et. Hace dos días que los ascensores están dañados. Renueva demanda habitacional. ¿Será prioritaria con gemelos de cuatro años + soltera? Relocación demanda $\mathrm{F}_{3}$ o $\mathrm{F}_{4}$ mismo sector...

Ver las demandas por escrito satisface en tanto la escritura es prueba de seriedad, una consideración aplicada que, como se espera, tendrá consecuencias.

Aunque la escritura del cuaderno sea muy parcial, permite ver diferentes fragmentos de la vida cotidiana del barrio. Líneas y rupturas biográficas de tal o cual familia o breves episodios residenciales se mezclan con problemas e incidentes de una naturaleza diferente: desperfectos técnicos, desempleo, conflictos vecinales; accidentes de trabajo. En desorden, Hélène escribe:

Aún no hay comerciantes en el recinto. Mal humor. El ascensor no funciona: salida de las escuelas: uno sólo funciona: hay que esperar: HASTA LA CORONILLA; Pta. Baja. Vecina 4 piso. Tira baldes de agua. Por problema con las palomas. Basureros. Daños ventana. Ver Sr. Montoro/Técnico.

La escritura es muy selectiva, lo que se escribe no es más que una parte de la realidad "vista a través del prisma de la subjetividad de quien escribe" (Lahire, B., 2008, p. I75). Pero el carácter 
fragmentario no se debe simplemente a la postura del profesional ni a la función de "borrador" profesional del cuaderno. Se debe también a la toma de palabra de los habitantes, a menudo telegráfica, que solo anuncia un fragmento de problema. De este lado también todo se enuncia a granel, sin ninguna jerarquía ni orden de prioridad. Las palabras son volcadas de manera brusca, entrecortada y fraccionada. No son relatos de vida sino anuncios, notificaciones o "avisos de paso". El cuaderno adopta el estilo de la urgencia ¿Podría ser de otra manera?

Prosigamos nuestra lectura. Algunos meses después de la apertura de las permanencias, leemos en el cuaderno:

Una mamá 7 calle Musset desde hace 27 años. $2^{\circ}$ piso. Sola tres hijos. Dos hijos 26 y 24 años. Trabajan y viven en casa. Una niña de siete años. Ella quisiera: un dept. De tres piezas para ella y su hija + un dpto. de dos piezas para sus hijos. Pide desde hace cuatro años. Se le contesta que realice un intercambio. Ella rechaza. Quiere tener una garantía para sus dos hijos. Inscripción resto du Coeur lunes 24/II ${ }^{11}$. Distribución 5/I2 (primera inscripción). Ella creían que era el I6/II. Accidente laboral hace dos años y medio. Tres operaciones en la rodilla: despido. Desde entonces, pequeñas misiones pero dolores. Horas de aseo de oficinas. Más o menos ayuda social 400 euros.

La pequeña biografía anotada por la profesional se extiende más de lo habitual, seguramente porque los problemas de los diferentes miembros de la familia se encadenan unos con otros. Hace cuatro años esta mujer renueva su demanda ante el organismo de vivienda social. Se le propone hacer un intercambio con otra familia pero "ella no quiere" ya que pretende una garantía: asegurar a cada uno de sus hijos una vivienda social, como una herencia o un derecho en el que cada hijo recibe, como devolución y en prioridad, un bien social. Esta idea (y esta práctica)

II. Servicio de asistencia alimentaria que existe en toda Francia y abre solo durante el invierno.

I2. Castel, R. (I995). La idea de propiedad social consiste en analizar todos los soportes jurídicos del derecho social en un continuum que, en total, crea una protección social al punto de devenir casi una propiedad.

de transferir un bien social a los hijos, trátese de un puesto de un pariente en el municipio, en el correo o en el hospital, es lo que R. Castel denomina una "propiedad social". ${ }^{12}$ En efecto, es frecuente observar a varias generaciones de una misma familia vivir en el mismo departamento o barrio de vivienda social, como la posesión de un estatus, el de "inquilino protegido" transmitido 
a sus hijos; en este caso, transmitirlo a los dos jóvenes-adultos que, en la imposibilidad de llegar a convertirse en inquilinos, devienen "albergados", sin estatus propio. Así, transferir un estatus a los hijos adultos es una forma de seguro. Podríamos decir que es el único "bien" que puede ser ofrecido como dote, como una herencia contractual. Más todavía, en este fragmento de relato puede leerse una transmisión en el tiempo, según las modificaciones de la familia, donde cada cual aspira a beneficiarse con un espacio de libre juego (Schwartz, O., I990), de cierta intimidad. Esta familia vive desde hace 27 años en aquella vivienda, los dos adultos jóvenes nacieron allí y realizaron toda su escolaridad y sus redes de amistad y su madre (que con seguridad tenga unos 50 años) no aspira a otra cosa que ver partir a sus hijos de casa y que el ciclo de vida familiar se desarrolle normalmente. Pero el ciclo se ha detenido y dicha anotación indica una situación común y usual: la adecuación imposible de la vivienda respecto de las transformaciones de las familias, la imposibilidad de constituir un espacio privado para cada uno de sus miembros, que es, como lo ha señalado N. Murard, un imperceptible pero preciso indicador de pobreza.

Algo similar le sucede a este hombre, que vive desde hace 23 años en la cité. Ya no sabe qué puerta golpear, va y viene por las ventanillas, busca el "modo de uso" correcto para obtener una vivienda más grande. Llega a la ventanilla protestando enérgicamente y poniendo todas "sus cartas" sobre la mesa. En el cuaderno leemos:

A. Demiragac. 2 calle Claudel. Fue a Bobigny. Se le dijo: iNo quedan viviendas! Lo toma a mal. Servicio de Viv. de la ciudad también se le dijo que hay que golpear a la puerta correcta -clientelismo. Varias demandas de vivienda pero quiere quedarse en este sector. Vive aquí desde 1987. Transparencia en las viviendas (atribuciones): por mes/por reservación. Carencia de informaciones. Problema de moho en las paredes: hijo enfermo (sin prioridad). No quiere una rehabilitación '8o Rosado, azul, verde.

Enfermedades infantiles, moho, solicitudes que se repiten, tiempos de espera inciertos. El Sr. Demiragnac va de ventanilla en ventanilla y llega a la oficina de la Renovación agotado e indignado. Hélène anota y toma partido o, al menos, no duda en escribir que fue mal recibido, insuficientemente informado y que existe un sistema clientelista. Saber golpear la puerta correcta 
supone conocer las claves y los nombres que llevan a la fila de los prioritarios. De forma espontánea, las familias creen encontrarse en una inmensa fila de espera en la que el que llega antes será el primero en ser atendido, pero descubren que no hay número para sacar y que nadie apunta el orden de llegada. Se instala la sospecha. Y queda escrito: lo que se cuestiona son las reglas de atribución; la primera de ellas debería ser la de proporcionar las instrucciones de uso del sistema.

\section{El escrito y la observación}

i presencia en el momento en que Hélène tomaba sus apuntes
ayuda a su comprensión y, sobre todo, a medir la fuerza de la
enunciación. La observación in situ nos permitió contextualizar estas palabras "escritas al vuelo" y comprender el peso de asuntos en apariencia menores, como un desperfecto de ascensor, una nueva solicitud de domicilio, la humedad entre dos muros que provoca enfermedades respiratorias, un alojamiento de larga duración que se vuelve tan insostenible como el recorrido infructuoso en las ventanillas.

Es el conocimiento del contexto por inmersión lo que permite reconstituir la "cadena" de problemas desde el punto de vista de la experiencia global de los habitantes, marcada por las restricciones y la urgencia. Es eso lo que diferencia nuestra mirada de la del historiador, quien no puede "hacer hablar" el archivo por aquellos que en él dejan huella. Al leerlos simplemente en el despacho personal, se vuelve difícil sentir la carga de estos escritos telegráficos, aunque el mismo archivo nos proporcione pistas para interpretarlo. En efecto, allí se encuentran repetidos los mismos problemas y sus consecuencias; las mismas inquietudes y enojos atraviesan todo el cuaderno. Mediante esta repetición, los "fragmentos de palabras" se vuelven inteligibles.

Vemos así cómo a través de este cuaderno menor, un borrador destinado a permanecer por años en un cajón, se acumulan las huellas de las quejas y reclamos expresadas en masa cotidianamente en una cité. Estos problemas surgen en el segundo corpus, el de las cartas dirigidas a los responsables de la vivienda, como grandes repeticiones perfiladas en los "recorridos": tanto en la ventanilla del Punto de Recepción de problemas habitacionales, como en la del guardia, la de la Municipalidad o la del Centro 
Social. Para muchos, las permanencias del Proyecto son la última etapa de sus trayectos de ventanilla en ventanilla. Cada petición sin efecto o sin respuesta eficaz en una oficina pareciera rebotar en el cuaderno. En este sentido, el cuaderno se inscribe en una red de escrituras adosadas a una amplia gama de instituciones sociales. Es allí donde todas estas inscripciones tienen sentido, pues desde el punto de vista de las familias el objetivo es golpear la puerta correcta y encontrar los buenos interlocutores para satisfacer tal o cual queja. Del lado de los inquilinos, se trata de un verdadero aprendizaje de las "instrucciones de uso" (a menudo oscuras) para alcanzar sus fines. Este aprendizaje es central y se transmite entre las mujeres, principalmente las madres, que toman la delantera de este "trabajo" en las ventanillas (Lahire, B., I993; Siblot, Y., 2006).

\section{Decodificar las cartas}

T

omemos ahora el segundo corpus: varios centenares de cartas dirigidas al organismo a lo largo de 20 años. Al leerlas una y otra vez, poco a poco descubrí diferentes tipos de problemas: el endeudamiento, la partida de los hijos que lleva a pedir una vivienda más chica, separaciones, divorcios y una situación que no creía tan frecuente: los alojamientos transitorios. Para facilitar la tarea, tomé de este corpus una sola serie, en la que es evocada la presencia de un "allegado" en un departamento. En efecto, numerosas familias albergan a miembros de la familia o a amigos que, solos o en pareja, con o sin hijos, desocupados o con empleos precarios, se encuentran por un período más o menos largo sin vivienda. Sin esta red, que les garantiza una última protección, estos albergados sin duda estarían en la calle, en una bodega o en una casa como "ocupantes precarios" (Bouillon, F., 2009). En este sentido, ser alojado por un tercero es un "mal menor", un estatus casi envidiable para aquellos que no lo consiguen. Sin embargo, a pesar de este soporte, cuando los albergados o los inquilinos toman el lápiz para dirigirse al organismo de vivienda social, este último se encuentra quebrantado. Cuando la situación dura meses y años, los vínculos penden de un hilo, se vuelven inestables y quebradizos (Laé, J-F. y Murard, N., I996). Puede que la fecha de partida ya haya sido fijada, pero ante la falta de salida, el último recurso es la escritura. 
Así, la urgencia de aquellas intimidades pulverizadas queda señalada en las cartas:

Señor, apelo a su bondad para pedir una vivienda social. Actualmente mi esposa espera un hijo y estamos siendo alojados por su tía, lo que implica muchos problemas de cohabitación. No tenemos intimidad, ni superficie vital que nos pertenezca, ni vida privada, aunque sí algunos problemas de humores. Solicito su atención con el fin de poner término a esta situación.

Y esta otra: "Considerando que aún no he recibido respuesta, le agradecería revisar mi expediente. Sentimos la necesidad de vivienda de manera apremiante, pues vivimos en casa de mi suegro con mi mujer y mi hija”. En ambas situaciones, entre la fuerza del parentesco y la excesiva cercanía física, los conflictos se vuelven el pan de cada día. Los niños son con frecuencia la piedra angular en la que se enuncian las tensiones. Los "albergados" comienzan a observar de cerca los movimientos y rotaciones de los departamentos, van a pedir noticias a los guardias y renuevan una y otra vez sus peticiones en las oficinas:

Señor director, tengo el honor de solicitar su buena voluntad. Hace un año realicé el trámite habitacional para un departamento de tres ambientes. Estoy de alojada en casa de mi hermana (el subrayado es original), tengo dos hijos, pedí una vivienda en la comuna. Estoy convencida que hay dos departamentos vacíos en la calle François Villon y quisiera una vivienda. No puedo lograr llevarme bien con mi hermana. Es un tres ambientes y el cuarto es muy pequeño para mí, mis hijos y sus hijos. No puedo poner mis cosas y no consigo ponerme de acuerdo con mi hermana. ¿Sería posible obtener una vivienda? Ya no puedo vivir más con mi hermana.

Madres, suegras, cuñados e hijas se ven en la necesidad de tomar el bolígrafo (o de delegar esa tarea) con el fin de dar parte a la oficina para protestar y pedir una intervención, una gracia o un favor, en nombre del derecho a un espacio privado y personal. En situación de alojamiento, la imposibilidad de tener una vida privada hace "estallar" las relaciones. Ser albergado durante las vacaciones o por un corto tiempo puede ser concebible y deseado, pero serlo bajo presión y por defecto, durante un período largo y sin fecha prevista de partida, exacerba tanto a quien da alojamiento como a quien lo recibe. Mientras el cuaderno se mostraba como la superficie de palabras telegráficas, los códigos y los 
tonos de interpelación en las cartas estaban cargados de sentido, tanto más cuando las observaciones los refuerzan. Es como si tuviéramos tres escalas diferentes, una superficie de palabras (el cuaderno), otra de frases (las cartas) y una tercera de tonalidades e intensidades corporales que marcan al investigador.

En la figura del alojado podemos observar una postura desfasada en caso de que participe del pago del arriendo. Podemos decir entonces que una parte de la "deuda" que caracteriza la situación queda reembolsada, sin por ello alcanzar a constituir una relación simétrica. También puede darse una cooperación en los gastos mobiliarios: la compra de un televisor o de una computadora. Cada albergado debe encontrar un modo de "indemnización” o de compensación para alivianar la deuda moral. Tomemos el ejemplo de esta mujer que escribe a la Oficina de Vivienda Social (HLM por su sigla en francés) para conseguir una propuesta de vivienda para la gente que alberga. Hace ya cuatro años que Charlotte Léa, sus hijos y su novio se encuentran alojados en casa de madame Delbois. Esta joven mujer participa con una pequeña suma de dinero en el pago del arriendo para atenuar la gran deuda que tiene con su anfitriona. Declara al encuestador del organismo, que viene a evaluar su situación económica, ser dueña de algunos muebles, lo que significa que estaría preparada para dejar el lugar y vivir en una vivienda propia. Demuestra además poder solventar un arriendo puesto que contribuye con parte del que paga la persona que la acoge. Ahora bien, aunque sea mesera en un café y reciba ayudas sociales, el encuestador desconfía:

Sra. Charlotte es empleada en una sociedad interina y pagada directamente por esta, lo que vuelve su empleo inestable. Debe proporcionarnos el último boletín de pago que haya sido 'entregado al municipio'. Considerando la inestabilidad del empleo, el arriendo corre el riesgo de quedar impago.

La cantidad de miembros regulares declarados son "tres personas", pero hay ocho que viven allí sin saber hasta cuándo la situación será posible. A pesar de la contribución mensual, la irritación crece entre el locatario y el allegado. Charlotte y la Sra. Dubois multiplican las demandas y permanecen en la lista de espera de la Municipalidad impacientes por recibir una respuesta. La Sra. Delbois se angustia con la idea de tener que "dejar en la calle" a esta familia. Hace tiempo decidió cambiar su 
departamento de cuatro piezas por una vivienda más pequeña y menos costosa de tres piezas. Pero sabe que la consecuencia de esta mudanza será la expulsión de sus allegados y con ello una gran decepción. No se decide a concretar el cambio, ya que, podemos suponer, las relaciones afectivas son fuertes, a tal punto que podríamos hablar de "adopción locativa” para expresar esta mezcla entre protección material
I3. La carta que transcribimos data de los años 80 , aunque forme parte de un expediente de actualidad. A pesar de la fecha de la correspondencia, señalemos que los tipos de quejas, las expresiones, las formas de interpelación no han variado desde entonces. Cuando consultamos series enteras de cartas de los últimos 20 años, constatamos que la forma y el contenido de las mismas son relativamente contantes. La crisis de la vivienda no es novedad, sobre todo en lo que concierne el sector social.

I4. El subrayado y la negrita figuran en la carta original.

I5. Antes de ser candidato presidencial y presidente de Francia, Jacques Chirac fue Alcalde de la ciudad de París.

y parental. Esta adopción locativa debe ser reemplazada por un nuevo vínculo, un contrato, otro soporte que impida a la familia alojada terminar en la calle, en un hogar temporal o como ocupante ilegal. La demanda es apremiante..$^{13}$ Leamos la carta que escribe la inquilina al organismo de vivienda:

29 de enero de 1980

Señor o Señora,

Tengo el placer de escribirle respecto a la persona que se encuentra alojada en mi casa. ${ }^{14}$ Se llama Srta. Charlotte Léa, madre de tres hijos de siete años, seis años y tres años, y que no tiene vivienda ni familia, entonces hace un buen tiempo que usted no le da una vivienda y entonces le escribo para decirle que a partir del is de febrero de 1980 ella no tendrá dónde dormir con sus tres hijos, le ruego entonces que la aloje aunque sea en una vivienda antigua - pues si no estuviera yo para recogerla de la calle, a dónde irá, me he dado cuenta de que usted cuenta conmigo porque ella se encuentra en mi casa.

Si el I6 de febrero de I980 ella está [sigue aquí] yo no pagaré el arriendo hasta que usted le dé alojamiento. Si se tratara de una guerra usted ya le habría mandado una convocatoria. Ella es francesa, es prioritaria con sus pequeños niños, así que si usted no le da alojamiento yo se la voy a llevar a ella con sus hijos y usted va a tener que arreglárselas para poder alojarla. He tenido bastante paciencia con esta historia y ya no puedo más. A partir del 15 de febrero de I980 ella estará a su cargo, yo se la llevo con sus cosas y sus hijos y se la dejo porque usted no sufre y el alcalde está al tanto, voy a ver al alcalde, el Señor Chirac, ${ }^{15} \mathrm{y}$ al Prefecto para preguntarle si una madre de familia de tres niños no tiene derecho a tener una vivienda, según una ley de i980, que ella se quede en una bodega con sus tres hijos, ella quisiera un departamento de tres o cuatro ambientes, aunque sea en los antiguos edificios así que esta es la 
última carta que le voy a escribir porque ya no tengo nada más que hacer con ella.

Aquí va mi dirección

Srta. Delbois Hélène 3, 4 Square Béranger Vivienda I870 I ${ }^{\mathrm{er}}$ piso.

Se trata de una carta de amenaza, con advertencias puntuales expresadas en negrita. Se pueden leer dos amenazas: una huelga de alquiler: "Si el I6 de febrero de I980 ella está yo no pagaré el arriendo hasta que usted le dé alojamiento", y una denuncia de la incompetencia del organismo a instancias jerárquicamente superiores (el Alcalde y el Prefecto). ¿Por qué? Porque la Sra Delbois considera cumplir una función que, desde su punto de vista, incumbe al organismo social: “...me he dado cuenta de que usted cuenta conmigo porque ella se encuentra en mi casa”. La dependencia (del organismo y de la madre con sus tres hijos) respecto a la inquilina debe ser sustituida por una relación contractual: “...A partir del I5 de febrero de I980 ella estará a su cargo, yo se la llevo con sus cosas y sus hijos y se la dejo". Ante la posibilidad de la bodega o de la calle, la Sra. Delbois exige el patrocinio del organismo, que considera comprometido por una obligación moral y jurídica: “...una madre de familia de tres niños no tiene derecho a tener una vivienda, si siendo una ley de i980 que ella se quede en una bodega con sus tres hijos, ella quisiera un $\mathrm{F}_{3} \mathrm{o}$ un $\mathrm{F}_{4}$ aunque sea en los antiguos edificios”. A pesar del enojo la carta está pensada. La referencia

I6. Podemos dar cuenta de esta escala de la siguiente manera: el inquilino, el sub-inquilino, el alojado que contribuye o coopera, el que no puede hacerlo, el ocupante sin título, el ocupante de bauleras y subsuelos y la persona en situación de calle. A cada forma de ocupación, corresponde un derecho, por mínimo que sea.

I7. Me enteré de esta información mediante una atenta lectura del expediente, ya que aparece en unas notas con lápiz a mina negro hechas por un empleado del organismo en los márgenes de la carta. También se lee en la encuesta realizada "en vistas a la eventual reubicación de candidatos allegados", adjuntada en el expediente. a la ley, que aparece con frecuencia en la correspondencia, da cuenta de las competencias de las familias para posicionar sus demandas en un universo normativo y sus casos en una escala de derechos. ${ }^{16}$ La Sra. Delbois llega incluso a callar su vínculo de parentesco con Charlotte Léa, su cuñada, probablemente para borrar las huellas de cualquier obligación moral presupuesta. ${ }^{17}$ De esta forma, la inquilina, una vez desvinculada de su allegada (su nuera), obliga a quien creó esta situación (el organismo social) a concretar un nuevo vínculo jurídico. Si la adopción queda rota, el patrocinio del estado social debe ejercerse. Lo uno deriva de lo otro. 
Era posible pensar que la inquilina iba a dejar el departamento en la fecha señalada y dejar "en la calle" a la familia allegada, dado lo insostenible de la cohabitación. Sin embargo, los informes de los encuestadores nos enseñan que la Sra. Delbois no se mudará en febrero sino en el mes diciembre de ese mismo año y no dejará a Charlotte, sus niños y sus cosas en la puerta de la oficina de vivienda. Muy por el contrario, dejará las llaves a su nuera para que ocupe, sin título ni derecho, el departamento. A falta de contrato, la ocupación. Leamos el informe del encuestador:

La inquilina ha sido realojada el I5 de diciembre en una vivienda de tres piezas en la Comuna. Dejó en su antigua residencia a la Sra. Charlotte y a sus hijos. La candidata no es solvente. No pudiendo obtener su expulsión, resulta conveniente trasladar a la ocupante a una vivienda más pequeña. La vivienda ya le fue propuesta por la comuna y ella afirma convenirle.

Porque los acuerdos entre las personas cercanas se realizan en los vacíos dejados por las instituciones, ellos no siempre pueden leerse en las cartas que dirigen a las oficinas. Estos acuerdos informales, así como los "recorridos" efectuados para tramitar las demandas, se aprecian mediante la lectura del conjunto de piezas que componen el expediente del locatario, a través de sus diferentes temporalidades. En el archivo de los albergados, esta interrelación temporal es impactante: pueden leerse, a la vez, las tácticas fugaces para conservar una legitimidad habitacional ante los propietarios, el conjunto de escritos dirigidos a obtener un certificado de albergue (lo que supone una participación en los gastos de la de vida doméstica y a veces del arriendo) e incluso, en un tiempo más prolongado, la "cesión en herencia" de un contrato de un locatario al momento de su partida.

\section{La historicidad en los escritos}

os expedientes de los inquilinos componen un archivo de larga duración ya que siguen a las familias durante IO, 20, 30 o más años, según cuánto lleven viviendo en el parque residencial. En este sentido, tienen una dimensión temporal excepcional que nos informa sobre los lineamientos de las familias, los momentos o acontecimientos que anteceden o suceden a gestos de escritura como los que acabamos de transcribir. Es la memoria de todas 
las peticiones, transformaciones familiares, incidentes con los guardias, los vecinos, la policía o, en ciertos casos, los tribunales. Así, se vuelve posible seguir los movimientos internos de una familia en relación a las instituciones y frente a los incidentes (una larga enfermedad que impide el pago de un arriendo, un marido que deja el domicilio conyugal, un niño en conflicto con la asistencia educativa de un tribunal, las quejas y peticiones sobre algún vecino, los reclamos sobre desperfectos materiales, los realojamientos que terminan mal, etc.) y a las soluciones encontradas.

Así como los relatos de familia, recogidos mediante entrevistas cara a cara, ayudarían a comprender el código entre "próximos" y las astucias para no hundirse en una pobreza aún mayor, los expedientes permiten seguir sus huellas porque registran insistentemente estos movimientos en una duración larga y sostenida. Más aún, el juego de escalas en la lectura de los expedientes (entre etnografía, sociología e historia) permite descubrir que hay diferentes temporalidades en un mismo archivo. En nuestro estudio, este cruce permite complejizar las relaciones entre las familias y la institución de vivienda social, inscribir el presente de una carta, con sus emociones, sus penurias, sus demandas, en un contexto más amplio de estrategias y trayectorias familiares y en la larga duración que liga los individuos a la propiedad social. Aquí reside la riqueza de estas fuentes, en la posibilidad de variar el "foco del objetivo", lo que implica no solo agrandar o disminuir el tamaño del objeto

I8. Sobre la variación de escalas de observación en las ciencias sociales, ver J. Revel, J. (I996). en el visor, sino modificar su forma y su trama. ${ }^{18}$

\section{Conclusión}

etomemos nuestra reflexión metodológica. Considerando que el sociólogo no provoca la situación o la interacción, los documentos disponibles son exteriores al investigador. Desde un punto de vista metodológico, la presencia del sociólogo no produce el acontecimiento. Nos encontramos provisoriamente en la postura del historiador o el archivista que toma el escrito tal como se le presenta. En este orden de ideas, podemos clasificar tres regímenes de intervención del sociólogo en la realidad: la 
entrevista como el producto de una interacción cara a cara, más o menos asimétrica, más o menos comprometida; la observación que recorta "viñetas expresivas" en las que el sociólogo es, a su pesar, un elemento activo y, lo que tal vez sería el grado cero de su presencia: el archivo. Por supuesto, su intervención se ejerce de inmediato en la selección, decodificación e interpretación. En todo caso, el sociólogo llega solo a posteriori con sus preguntas y proyecciones.

Correlatos de lugares y actividades, la existencia banal de estos documentos "menores" pasa la mayoría de las veces desapercibida para el etnógrafo en terreno y su exploración suele parecer imposible debido a su densa encriptación. Por medio de informes, encuestas, cartas de petición y quejas, la escritura acompaña la acción de los profesionales, así como los trámites y problemas de los individuos. ${ }^{19}$ Tenemos ahí, de ambos lados, una puesta en discurso de lo cotidiano. Desde la perspectiva de sus propios autores, esos textos, descripciones y conminaciones buscan cierta eficacia social. No se trata simplemente de seguir un orden de registro sino de señalar una realidad (desgracias, desórdenes, irregularidades) con el objetivo de modificarla. ${ }^{20} \mathrm{~A}$ nuestro parecer, y a pesar de sus dificultades - acceso restringido, secreto profesional, archivos sin archivar- la ventaja del documento radica en que ofrece un punto de vista original sobre la vida cotidiana, principalmente sobre las relaciones con las instituciones y se muestra revelador de una "escena interior" que toca

\begin{abstract}
I9. Sobre esta correlación de los documentos personales y profesionales con las actividades llevadas a cabo, veáse Laé, J-F. y M. Kempeneers (ed.). (2008).

20. Esa es la pretensión de todo acto de escritura. A propósito, para M. de Certeau la escritura es "esa actividad concreta que consiste en construir un texto, en un espacio propio, la página, que tiene el poder sobre la exterioridad de la cual ha sido previamente aislado" (De Certeau, M., I990).
\end{abstract} con precisión puntos sensibles y escasamente evocados, como la vida material, la insalubridad, la posición de los allegados, acorralados entre el estatuto de locatario y de ocupante ilegal, entre otros.

$\mathrm{Al}$ abordar estos dos corpus textuales pretendí demostrar que existe una continuidad entre ambos, que la correspondencia y el cuaderno son como dos pasillos en comunicación recíproca. Podríamos encontrar estas mismas protestas, reclamos, enojos en otras oficinas y cuadernos, en las empresas de seguro, los tribunales, el Polo de Empleo o el Centro Social del barrio. Esta hipótesis de una "red de escrituras" permite formular otra hipótesis que 
concierne al trabajo invisible de las familias, "los recorridos por las ventanillas". En otros términos, se trata de la idea de que las familias no se conforman con una sola demanda, cuya respuesta suele ser incierta, sino que la lle-

2I. A partir de una investigación de terreno en la periferia de Buenos Aires, D. Merklen ha trabajado sobre la figura del " cazador urbano » para describir las estrategias en las instituciones y los recorridos en la ciudad realizados por individuos desempleados con el fin de asegurar la subsistencia cotidiana (Merklen, D., 2005). van de ventanilla en ventanilla convencidas de poder acceder a derechos sociales por medio de la repetición. ${ }^{21}$ Si lográramos juntar y reconstituir el conjunto de estos escritos dispersos, tal vez descubriríamos más en detalle el trabajo de las familias en la búsqueda de recursos. Escribir a las instituciones, ¿no es acaso una manera de dejar huellas de este trabajo de supervivencia y un medio para ser escuchado?

Para terminar, estos dos corpus documentales plantean una pregunta a las prácticas sociológicas, etnográficas e históricas en sus intentos por reconstituir experiencias y condiciones de vida. El uso de fuentes administrativas es débil en cuanto a la exploración de las relaciones sociales (en este caso, la relación allegado/ inquilino/propietario), los modos de vida, las formas de pensar, los modos de acceso a derechos, las trayectorias familiares y los conflictos cotidianos. Sin embargo, el cruce de estas miradas permite despejar ese archivo administrativo compuesto de prácticas, biografías administradas y demandas hasta entonces postergadas. Cada una de estas miradas fabrica su propia escala contextual, con una amplitud temporal más o menos grande y una atención diferente a la singularidad, la fuerza y la capacidad de acción de los individuos. La atención etnográfica dilata el instante presente de un gesto de escritura y captura el momento fugaz de la toma de palabra. El etnógrafo acerca su lupa al archivo para aprehender cada detalle significativo. La mirada sociológica inscribe dicho momento en una estrategia más amplia, en un conjunto de relaciones sociales y de escritos administrativos. Finalmente, el régimen histórico retiene los destinos individuales adosados a la larga duración del derecho social. Por supuesto, el cruce de estas miradas existe en muchos trabajos; pensemos simplemente en la microhistoria de C. Ginzburg, J. Revel o A. Corbin, caracterizada por la atención etnográfica en la lectura de los archivos. La capacidad de descomponer los múltiples tiempos y de atender a los diferentes contextos en un mismo corpus de archivo no es privilegio exclusivo de alguna disciplina. Lo importante no es 
la prioridad de una mirada sobre otra sino la articulación entre estas diferentes temporalidades y contextos que no dejan de afectarse entre ellos. Comprendemos así que variar las escalas de lectura sea un recurso heurístico fundamental, que permite dar cuenta de la estructura fundamentalmente "laminada" de lo social (Revel, J., I996).

De ello se desprende una suerte de archivo personal y administrativo, en el sentido en que se fijan momentos, relaciones, gestos y prácticas cotidianas, un testimonio irremplazable sobre el pasado y el presente. ${ }^{22}$ En lugar de ver al archivo administrativo como una fortaleza fría e impersonal, abogamos por despejar de este archivos familiares y biográficos, comportamientos y voces individuales. La exhumación de estos destinos personales permitiría poner en cuestión la supuesta coherencia de la maquinaria administrativa, esa tradicional visión holística de "lo social" propia tanto del sociólogo 22. Sobre la vertiente personal de los archivos administrativos, ver las reflexiones de J-F. Laé (20I0), también el número temático editado por Artières, Ph., y D. Kalifa (Ed). (2002). como del historiador. No se trata de ceder a una visión individualista sino de pensar que este tipo de archivos, con sus fragmentos de experiencias y de relaciones complejas, participan desde su lugar de lo social y lo institucional, aportando una versión diferente, discreta, compleja.

Si ponemos el acento en las escrituras menores, los recorridos singulares, los momentos en que los individuos riñen con la institución social, se abre entonces una multiplicidad de experiencias que critican al modelo burocrático. Habiendo hecho estallar este esquema holístico, el paciente trabajo de desciframiento realizado por el etnógrafo de las escrituras recobra todo su sentido: realizar una historia y una sociología de los fragmentos y de la textura compleja del archivo.

\section{ReFerencias}

Artières, P. (1998). Clinique de l'écriture. Une histoire du regard médical sur l'écriture ordinaire. Paris: Les Empêcheurs de penser en rond.

Artières, P. (2000). Le livre des vies coupables. Autobiographies de criminels (1896-I909). Paris: Albin Michel.

Artières, Ph., y D. Kalifa (Ed). (2002). Histoire et archives de soi. Sociétés et Représentations. CREDHESS, I3, Avril. 
Boulluon, F. (2009). Les mondes du squat. Anthropologie d'un habitat précaire, Paris: PUF.

Castel, R. (1995). Les Métamorphoses de la question sociale. Une chronique du salariat, Paris: Fayard. Trad. En lengua española: (I997). Las metamorfosis de la cuestión social. Buenos Aires: Paidós.

De Certeau, M. (I990). L'invention du quotidien. i. Arts de faire. Paris: Folio, essais Gallimard.

Dubois, V. (1999). La vie au guichet. Relation administrative et traitement de la misère. Paris: Economica.

Fabre, D. (I993). Ecritures ordinaires. Paris: Centre Georges-Pompidou/ P.O.L.

Fabre, D. (1997). Par écrit. Ethnologie des écritures quotidiennes. Paris: M.S.H.

FAURE, S. (2006). De quelques effets sociaux des démolitions d'immeubles. Un grand ensemble HLM à Saint Etienne. Espaces et sociétés, I24I25, I9I-206.

LaÉ, J-F., Murard N. (I996). Célibataire à la rue. Actes de la recherche en sciences sociales, II3, 3I-39.

LAÉ, J-F. (2008a). Les nuits de la main courante. Ecritures au travail. Paris: Stock.

LAÉ, J-F. (2008b). Le clapotis des mots gracieux. Sociologie et sociétés, $4 \mathrm{O}(2)$.

LAÉ, J-F. (20IO). Sorties du silence: les écritures mineures? En Payet, J-P., C. Rostaing, C., Giuliani, F. La relation d'enquête. La sociologie au défi des acteurs faibles. (pp. I23-I32). Rennes: Presses Universitaires de Rennes.

LAÉ, J-F., y M. KEMPENEERS (ed). (2008). L'archive personnelle, la grande oubliée. Sociologies et sociétés. Les Presses de l'Université de Montréal, XL(2), Automne.

LAHIRE, B. (I993). La raison des plus faibles. Rapport au travail, écritures domestiques et lectures en milieux populaires. Lille: Presses Universitaires de Lille.

LAHIRE, B. (2008). De la réflexivité dans la vie quotidienne: journal personnel, autobiographie et autres écritures de soi. Sociologies et sociétés, XL(2), I65-I79.

Merklen, D. (2005). Pobres ciudadanos. Las clases populares en la era democrática. Buenos Aires: Gorla.

PoHn, A. (2009). Faire famille: les écritures de travail en centre de rapatriement. Semen: Revue de Sémiolinguistique des textes et discours, 28, 53-72. 
Revel, J. (I996). Jeux d'échelles. La micro-analyse à l'expérience. Paris: Gallimard Le Seuil.

Schwartz, O. (I990). Le monde privé des ouvriers. Paris: PUF.

SiBLOt, Y. (2006). 'Je suis la secretaire de la famille!' La prise en charge féminine des tâches administratives. Entre subordination et ressource. Genèses, 64, 46-66.

WELLER, J-M. (I999). L'Etat au guichet. Sociologie cognitive du travail et modernisation administrative des services publics. Paris: Desclée de Brouwer. 
